DIW BERLIN

Discussion

Papers

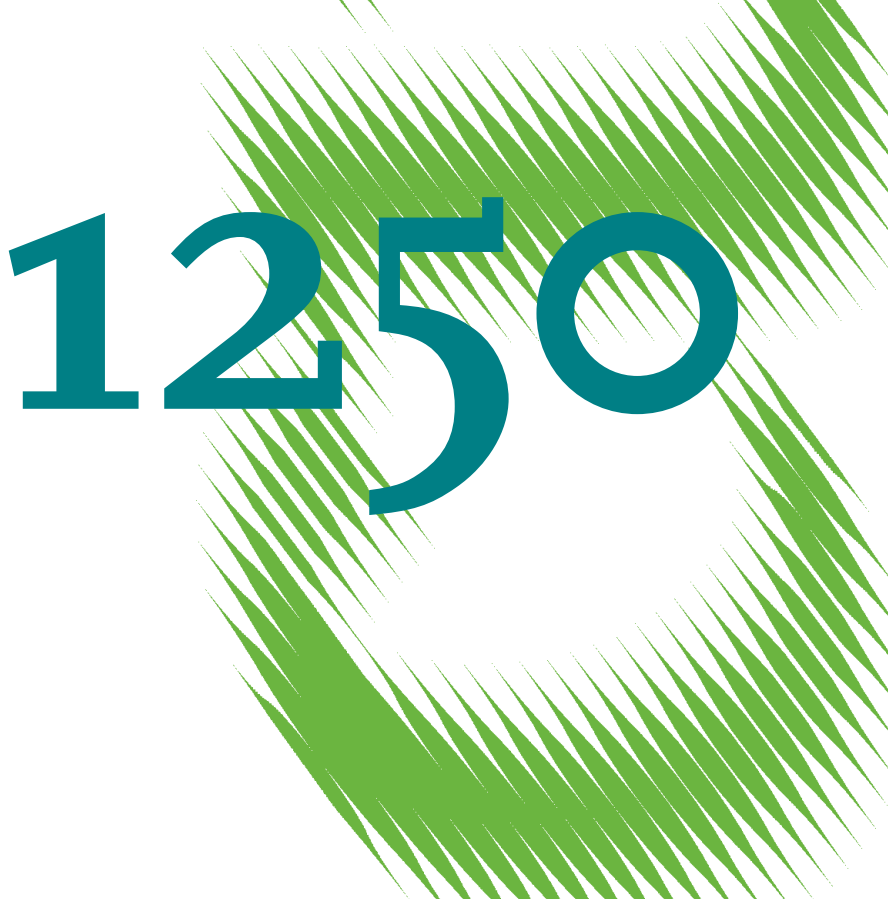

Integrated Electricity Generation Expansion and Transmission Capacity Planning

An Application to the Central European Region 
Opinions expressed in this paper are those of the author(s) and do not necessarily reflect views of the institute.

IMPRESSUM

(C) DIW Berlin, 2012

DIW Berlin

German Institute for Economic Research

Mohrenstr. 58

10117 Berlin

Tel. $+49(30) 89789-0$

Fax +49 (30) $89789-200$

http://www.diw.de

ISSN print edition $1433-0210$

ISSN electronic edition 1619-4535

Papers can be downloaded free of charge from the DIW Berlin website:

http://www.diw.de/discussionpapers

Discussion Papers of DIW Berlin are indexed in RePEc and SSRN:

http://ideas.repec.org/s/diw/diwwpp.html

http://www.ssrn.com/link/DIW-Berlin-German-Inst-Econ-Res.html 


\title{
Integrated Electricity Generation Expansion and Transmission Capacity Planning: An Application to the Central European Region
}

\author{
Andreas Schröder ${ }^{1}$ \\ Maximilian Bracke
}

\begin{abstract}
This article presents an integrated electricity dispatch and load flow model with endogenous electricity generation capacity expansion. The target is to quantify generation capacity requirements for 2030 and where within Central Europe it shall be ideally placed when taking into account the projected grid structure. We explicitly model the interdependence between grid operation and power plant placing as we investigate the contribution of centralized power plant placement on reducing the need for grid expansion. The application focuses on Germany and its neighbors and reference is made to recently published plans on grid expansion (TSO 2012). We adopt the perspective of a welfare maximizing system planner and thus determine capacity expansion levels as first-best benchmark. Results show that optimal capacity expansion levels are much lower than previous studies indicate (e.g. dena (2008); EC (2011); EWI et al. (2010); Maurer et al. (2012)). We also show that the need for grid expansion can be reduced by the appropriate placing of just a few Combined Cycle Gas Turbine (CCGT) power plants as well as the use of storage and Demand-Side-Management. The presence of intra-national HVDC lines as proposed in the Grid Development Plan of 2012 (TSO 2012) is found to significantly reduce overall congestion and the need for back-up power plants. However, the contribution of the proposed HVDC lines varies greatly from project to project, calling for a prioritization of plans.
\end{abstract}

Keywords: electricity, network planning, renewable energies, electricity markets, capacity investment

JEL classification: D61, D85, C61, Q42

\footnotetext{
Version of 31 October 2012. This document was prepared in the framework of the project "Modeling the Energy Transformation", supported by the Stiftung Mercator (2012-2015).

${ }^{1}$ Corresponding author at: DIW Berlin, 10108 Berlin, Germany, Phone: + 49177 1984566, Fax: + 493089789 200; Email addresses: aschroeder@diw.de (A. Schröder), maximilian.bracke@students.uni-mannheim.de (M. Bracke).
} 



\section{Introduction}

While the expansion and coordination of power transmission capacities remains an important focus of network planning, stakeholders are increasingly concerned with the future composition of the power generation mix as a whole and its interdependence with transmission grid planning. The optimal combination of different types of plants that accounts for the specific characteristics of an energy system dominated by renewable sources (RES) has yet to be determined.

Most stakeholders agree that securing RES integration calls for the expansion of power plant capacities as back-up reserves in addition to the expansion of transmission capacities (ENTSO-E 2009). An important and unanswered question, though, is how this additional capacity will be composed and its optimal geographical distribution. Numerous studies have - at least in part - dealt with the optimal amount of generation capacity expansion but they have shortcomings in terms of infrastructure representation. In particular, the available literature gives no or only vague information concerning transmission grids, the supply of reserve capacities and the geographical allocation of plants. In this paper we therefore propose a more detailed approach on interactions between network planning and power plant investment. We apply a welfare maximizing model for Germany and Central Europe in order to determine how many back-up power plants of which specific type will be needed in the medium term, given the grid structure of 2030. Our model also provides details on the optimal geographical distribution of the future generation system and its impact on grid congestion. This information is of great importance when allocating new back-up plants within the energy grid. As benchmarks for the future expansion of RES generation have already been set in Europe, we take a special focus on the expansion of conventional capacities. Our aim is to investigate which conventional energy resource best fits into the future grid dominated by RES, how many additional plants of this type are needed to provide energy security at reasonable costs and where they should be best placed. Furthermore, we investigate how the different flexibility options (i.e. storage, demand-side-management and back-up power plants) affect congestion patterns in the electricity grid and what that means for the recently proposed grid expansion projects in Germany (TSO 2012).

The rest of the paper is organized as follows. Section 2 gives a short overview on the current literature on energy network planning and capacity expansion in Germany and Europe. Section 3 briefly outlines the model applied in this study while Section 4 provides details on the data used. Scenarios are outlined in Section 5. Results are presented in Section 6 and some conclusions from our findings as well as a summary can be found in Section 7 .

\section{Literature review}

Numerous studies deal with the future development of conventional generation capacity in the German energy grid and - using various types of models - their conclusions and methodical disadvantages differ significantly. The majority of studies suggest that even with a continuous increase of renewable generation capacity, there will still be a need for the installation of additional conventional power plants.

In a detailed discussion on future capacity adequacy, Maurer et al. (2012) claim that there is a need for at least $19 \mathrm{GW}$ additional generation capacity for Germany. The analysis is based on a model that adopts a national 'autark' view of system adequacy and no indication is given to the expansion need under an integrated European market regime. As many other studies, Maurer et al. (2012) omit the importance and benefits of integration of spatially separated electrical systems with different generation mixes, as pointed out by Scorah et al. (2012). 
The Kurzanalyse Kraftwerksplanung (dena 2008) optimizes power plant expansion under exogenous demand but it is not specific on their geographic allocation. The analysis considers an increasing need for reserve energy (from $0.84 \mathrm{GW}$ positive and $0.6 \mathrm{GW}$ negative in 2003 to $3.2 \mathrm{GW}$ positive and 2.1 GW negative in 2015) and predicts a need for additional conventional plant capacity (coal and gas) of 10 to $14.2 \mathrm{GW}$ in 2020. Another study by dena (2010) delivers more differentiated conclusions. Using the DIME model - in which power demand is again determined exogenously - it predicts that the capacity of all conventional power plants will decrease except for lignite-fired plants which is supposed to increase from 20.4 GW in 2005 to $24.3 \mathrm{GW}$ in 2020. According to the authors, even though gas-fired power plants might provide necessary flexibility, they would be replaced by modern and more efficient new coal-fired plants due to high gas prices. However, even though the study builds on a strong data basis regarding infrastructure, it neither specifically optimizes the power plant fleet nor does it go beyond a 2020 horizon.

The Potsdam Institute for Climate Impact Research (Knopf et al. 2011) uses the model MICOES to determine a need for increased fossil fueled power generation capacity by $8 \mathrm{GW}$ in addition to already planned power plants. It does not model plant construction as endogenous variable though. The Potsdam Institute also uses LIMES (Markus Haller et al. 2012), a simultaneous grid and generation expansion model which minimizes power system costs. Here, power demand is exogenously determined through existing projections and capacity expansion is endogenous. The grid representation in the model is aggregated showing nation-by-nation Net Transfer Capacity (NTC) values as well as employing a piping model rather than a power flow model. In a transmission expansion scenario the authors consider Germany to use large energy imports from Northern Europe to balance demand fluctuations and thus become a net importer of energy. Nevertheless, the LIMES model results project massive gas power plant expansion for Germany in the order of 20 - $30 \mathrm{GW}$ by 2030. These values take into account projected transmission grid expansion and, thus, improved European market integration.

On the European level, the Energy Roadmap 2050 (EC 2011) offers a comprehensive impact assessment of several policy scenarios. It uses PRIMES and a set of complementing models defining macroeconomic developments in order to determine the market equilibrium for energy demand and supply. Due to intermittency of RES production, additional investment in conventional capacity is predicted to be necessary with the amount depending on which of the outlined policy pathways is chosen. Installed gas-fired power capacity is supposed to increase across all policy scenarios while coal-fired energy capacity decreases in most scenarios. Other studies point into the same direction. The World Energy Outlook (IEA 2011) takes a global perspective using the World Energy Model (WEM) and predicts additional installation of conventional energy capacity in Europe from 2011 to 2035 mainly in the field of gas-fired plants (139 GW) and coal-fired plants (67 GW). Elberg et al. (2012) use the DIMENSION simulation model for the European electricity market and find that gas-fueled generation capacity will almost double to 55 GW in 2030 while investment in other conventional resources declines. Unfortunately, neither of these studies gives information on the preferred allocation of power plants within Europe or Germany.

Some studies specifically consider uncertainty in energy supply from fluctuating renewable resources. Nagl et al. (2012) develop a stochastic combined investment and dispatch model with uncertainty in the feed-in of wind and solar energy sources and apply it to the European electricity system. The objective of the piping model formulated as Linear Programming (LP) is to minimize total system costs. It thus adopts a system perspective and takes into account correlations between solar and wind feed-in. Capacities of conventional power plants are projected to decrease for coal and nuclear power and increase for gas power plants. 
Only few studies provide implications on the optimal geographic distribution of power plants in Germany. One of these is presented by Dietrich et al. (2010) who analyze power plant placing in Germany with ELMOD under nodal pricing and in a system cost minimization approach with 12 time slots included at the dispatch stage. In a welfare case where a benevolent planner is assumed to minimize costs, power plants are mostly placed in the south-western part of the country and on the northern coast line when taking a national perspective. However, when allowing for multinational planning, the study sees much more capacity investment in Lower Saxony and North Rhine-Westphalia, especially close to the Benelux border in order to relieve cross-border congestion.

In the models currently used to predict developments in composition and distribution of the power plant fleet in Germany, three general disadvantages arise from the preceding overview. First, most applications minimize costs rather than maximizing welfare which could give detailed insight into preferable energy policies by setting a benchmark. Second, none of these models considers demand as price-sensitive and partly controllable input factor, although demand-side-management tools (DSM) gain importance in electricity markets. In a market economy, the correct depiction of demand should be given more consideration. Third, no study gives very detailed implications on the desirable allocation of conventional power plants in Germany. Bearing in mind the significant problems of transmission, this is a crucial question to be answered. All three gaps could be filled by a model proposed in this paper. An additional value of this work stems from our novel consideration of German electricity grid expansion plans outlined in the TSO proposal of June 2012 (TSO 2012). Most previously mentioned studies omit the interaction between transmission grid planning and power plant placing. We explicitly model the interaction between transmission projects flexible alternatives (i.e. Storage, DSM, back-up power plants).

\section{Model formulation}

Our electricity market model is formulated as Quadratically Constrained Problem (QCP). It maximizes a social welfare function which is subject to several constraints and facing a price elastic demand function. The model is an evolution derived from Boldt et al. (2012) which in turn uses the ELMOD model developed by Leuthold et al. (2012). This DC load flow approach is superior to simple piping models (EC 2011; M. Haller 2012) because it accounts for loop flows, a peculiar characteristic of electricity flows. The lossless DC load flow model here is formulated on the basis of Power Transfer Distribution Factors (PTDF), which indicate the amount of power flow at each line in dependence of power injection at some specified hub. DC lines are treated separately from AC lines as they are assumed to be point-to-point connections not causing loop flows.

The model also includes various storage technologies. It implements a stepwise cost function for Demand-Side Management (DSM) in order to realistically represent this feature of a flexible energy market. A restriction is imposed so that load can be shifted only within a certain time frame.

A detailed description of the model used is given in Boldt et al. (2012) so we will only briefly recapitulate it here. In order to maximize social welfare we solve the following problem

$$
\begin{aligned}
\max W=\sum_{t}\left(q_{\text {area }}(t)-\operatorname{Cost}_{\text {var }}(t)\right)-\sum_{t, s, n} g_{\text {up }}(t, s, n) \cdot \operatorname{Cost}_{\text {ramp }}(s) \\
\quad-\sum_{t, n} \operatorname{Cost}_{D S M}(s) \cdot \operatorname{DSM}_{\text {OUT }} l, m, h \\
(t, n)-\sum_{s, n} I(s, n) \cdot \operatorname{Cost}_{I N V E S T}(s, n)
\end{aligned}
$$

where the demand function may be described as 


$$
q_{\text {area }}(t)=\sum_{n} a(t, n) \cdot q(t, n)+0.5 \cdot m(t, n) \cdot \sqrt{q(t, n)}
$$

with the slope

$$
m(t, n)=\frac{p_{r e f}(t)}{\varepsilon \cdot \lambda \cdot q_{r e f}(t)}
$$

and the intercept

$$
a(t, n)=p_{\text {ref }}(t)-\lambda \cdot q_{\text {ref }}(t) \cdot m(t, n) .
$$

When solving Eq. (1) several energy balance constraints have to be accounted for. The nodal balance constraint has to be true for any node at any point in time

$$
\begin{aligned}
\sum_{S} G(n, s, t)+ & \text { wind }_{\text {max }}(t, n)+\text { hydro }_{\max }(t, n)+p v_{\max }(t, n) \\
& +\sum_{s t}\left(S_{I N}(s t, n, t)-S_{\text {OUT }}(s t, n, t)\right)+A C_{\text {netinput }}(t, n) \\
& +D C_{\text {netinput }}(t, n)+\operatorname{DSM}_{\text {OUT }_{l, m, h}}(t, n)-D S M_{I N, m, h}(t, n)-q(t, n) \\
& =0
\end{aligned}
$$

as well as the generation constraint

$$
G(t, s, n) \leq \operatorname{rev}(s) \cdot\left(G_{\max }(n, s)+I(s, n)\right),
$$

the cost function

$$
\operatorname{Cost}_{v a r}(t)=\sum_{s, n} G(t, s, n) \cdot c(s),
$$

the ramping constraints

$$
\begin{gathered}
\operatorname{Lim}_{\text {ramp }} \geq G(t, s, n)-G(t-1, s, n), \\
\operatorname{Lim}_{\text {ramp }}=\operatorname{Perc}_{\text {ramp }} \cdot G_{\text {max }}(n, s),
\end{gathered}
$$

and the definition of the ramping variable

$$
g_{u p}(t, s, n) \geq G(t, s, n)-G(t-1, s, n) .
$$

As we model a power market with both AC and DC flows, we account for AC flow constraints

$$
\begin{gathered}
A C_{\text {lineflow }}(l, t)-\sum_{n} p t d f(l, n) \cdot A C_{\text {netinput }}(t, n)=0, \\
-A C_{p_{\text {max }}}(l) \leq A C_{\text {lineflow }}(l, t) \leq A C_{p_{\text {max }}}(l), \\
\sum_{n} A C_{\text {netinput }}(t, n)=0
\end{gathered}
$$

as well as for DC load flow constraints 


$$
\begin{gathered}
\sum_{d c l} D C_{\text {lineflow }}(d c l, t)=0 \\
-D C_{p_{\text {max }}}(d c l) \leq D C_{\text {lineflow }}(l, t) \leq D C_{p_{\text {max }}}(d c l) \\
D C_{\text {netinput }}(t, n)-\sum_{n} D C_{\text {netinput }}(t, n) \cdot D C_{\text {incidence }}(d c l, n)=0 .
\end{gathered}
$$

The $\mathrm{n}-1$ security criterion is approximated by reducing the capacity of each AC line by a transmission reliability margin (20\%). Note that the model neglects transmission losses. This is done to keep the model tractable and to omit non-linear elements where possible.

Regarding the implementation of storage technologies, the model considers storage power limits

$$
\begin{gathered}
S_{I N}(s t, n, t)-S_{I N_{\max }}(s t, n, t) \leq 0, \\
S_{\text {OUT }}(s t, n, t)-S_{\text {OUT } \max }(s t, n, t) \leq 0
\end{gathered}
$$

and storage capacity limits

$$
S_{L E V E L}(s t, n, t)-\left(S_{L E V E L}(s t, n, t-1)-S_{O U T}(s t, n, t)+S_{I N}(s t, n, t) \cdot S_{e f f}(s t)\right) .
$$

We use the formulation of a storage state variable which indicates the state-of-charge.

$$
S_{\text {cap }} \text { max }(s t, n) \geq S_{L E V E L}(s t, n, t)
$$

An overall balance guarantees that the storage device left at the same state-of-charge as in the beginning.

$$
\sum_{t} S_{I N}(s t, n, t) \cdot S_{e f f}(s t)-S_{O U T}(s t, n, t)=0
$$

DSM constraints for different cost segments restrict the amount of shiftable load

$$
\begin{aligned}
& D S M_{I N_{l, m, h}}(t, n)-D_{S M_{M A X} l, m, h}(t, n) \leq 0, \\
& D S_{\text {OUT }_{l, m, h}}(t, n)-D_{M A M_{l, m, h}}(t, n) \leq 0
\end{aligned}
$$

A balance condition ensures that load is shifted only within a certain time frame $t-1$ and $t+1$

$$
D S M_{I N, m, h}(t-1, n)-D S M_{\text {OUT }}{ }_{l, m, h}(t+1, n)=0 .
$$

Finally, an additional constraint ensures that total yearly demand equals the predetermined level $\mathrm{x}$ (TWh).

$$
\sum_{t, n} q(t, n)=x T W h
$$

The QCP is coded in the GAMS modeling environment. The size of the application here (10.1 GB) makes it necessary to use advanced computers. Computation times with facilities available at DIW Berlin (64-bit Linux, 32 kernels, 3 GHz CPU, 512 GB Ram) range in the order of 11-33 hours, including data compilation and export. 


\section{Data}

In general it was taken care to align assumptions to the National Grid Development Plan (TSO 2012) so as to allow for a comparison of results. As the Grid Development Plan does not provide a lot of detailed information on assumptions and used data, some input assumptions of the model used here deviate from the TSO Plan.

\section{Geographic coverage}

The model application covers Central Europe with 41 nodes. 18 thereof lie in Germany, in line with the dena-Zones established based on congestion patterns in the seminal dena-II-study (dena 2010). All countries other than Germany and Denmark are represented with one node only.

\section{Temporal coverage}

The model is applied to the European electricity system as we expect it to be in 2030. Within the fictive year 2030, an hourly dispatch of the whole year (8760h) is optimized.

\section{Generation}

The model application includes six dispatchable generation technologies plus must-run feed-in of wind, solar and hydro plants. Inflexibilities in the dispatch of fossil-fired and nuclear power plants are reflected by constraints on load gradients and ramping cost. Variable costs are in line with assumptions in the TSO report and produce a merit order curve plotted in Figure 1. Since the model is applied to the year 2030, assumptions are made on the generation capacity available by 2030. The PLATTS European power plant database (Platts 2011) is used as basis to exogenously determine the retiring dates for all power plants in Europe and thereby attain remaining generation capacities. We expect over $60 \mathrm{GW}$ of installed conventional capacity to retire within Germany by 2030 (compared to 104 GW base level in 2010) which is almost double the 33 GW expected in Maurer et al. (2012). Information on energy plants found in Platts (2011) is combined with geographical information of DENA zones to allocate power plants to zones. Capacities deviate between the National Grid Development Plan (TSO 2012) and our assumptions. Scenario B 2032 of the Grid Development Plan is characterized by a high amount of new gas power plant capacities in Southern Germany. The report does not specify how it determines the amount of new capacity and where exactly it is placed. We therefore opt to base or own assumptions on Platts (2011) and optimize the distribution and technology choice of new capacities endogenously. Table 1 provides further details on the base assumptions.

Table 1: Generation capacities in Germany in the reference scenario.

\begin{tabular}{|l|c|c|}
\hline in GW & $\begin{array}{l}\text { Grid Development } \\
\text { Plan Scenario B } \\
\text { 2032 (TSO 2012) }\end{array}$ & $\begin{array}{l}\text { Own estimations } \\
\text { on the basis of } \\
\text { Platts (2011) }\end{array}$ \\
\hline Lignite & 13.9 & 9.0 \\
\hline Coal & 21.2 & 20.6 \\
\hline Gas & 40.1 & 8.4 \\
\hline Oil & 0.5 & 0.8 \\
\hline Nuclear & 0 & 0 \\
\hline Biomass & 9.4 & 9.4 \\
\hline
\end{tabular}


Table 2: Wind and solar production 2005-2011 in Germany.

\begin{tabular}{|l|c|c|}
\hline & $\begin{array}{l}\text { Wind Index } \\
\text { (IWR 2012) }\end{array}$ & $\begin{array}{l}\text { Solar Index } \\
\text { (SFV 2012) }\end{array}$ \\
\hline 2005 & $-12.8 \%$ & $+1 \%$ \\
\hline 2006 & $-3.9 \%$ & $+3 \%$ \\
\hline 2007 & $+2.7 \%$ & $+3 \%$ \\
\hline 2008 & $+1.7 \%$ & $+2 \%$ \\
\hline 2009 & $-9.2 \%$ & $+2 \%$ \\
\hline 2010 & $-25.1 \%$ & $-4 \%$ \\
\hline 2011 & +2.3 & $+9 \%$ \\
\hline & $\begin{array}{l}\text { Deviation from } \\
\text { rolling 10-year } \\
\text { average }\end{array}$ & $\begin{array}{l}\text { Deviation from } \\
2005-2012 \\
\text { average }\end{array}$ \\
\hline
\end{tabular}

The growth of renewable energies in all countries else than Germany is based on projections of productions outlined in EcoFys et al. (2011) which are based on National Renewable Energy Action Plans (NREAP). Construction of feed-in time series for fluctuating renewable energy resource is based on meteorological information (Dee et al. 2011; Eurostat 2011) and actual production data of Germany from 2011. Calculations are based on the reference year 2011 as this year represents a relatively good average year in terms of wind production in Germany, see Table 2. Further details on the derivation of power output from solar radiation and wind speed data can be found in Boldt et al. (2012). The time series expose a German peak demand of 84 GW just as in the TSO grid plan. Maximal residual load of reference demand is $76.2 \mathrm{GW}$ on a November day, peak simultaneous feed-in of solar and wind power amounts to $106.7 \mathrm{GW}$ (with $157 \mathrm{GW}$ installed capacity), the minimum lies at $1.4 \mathrm{GW}$. Peak excess supply of solar and wind feed-in amounts to $33.1 \mathrm{GW}$. Note that these figures refer to reference demand. As demand is endogenous and price-sensitive in the model, deviations can occur in the resulting actual demand.

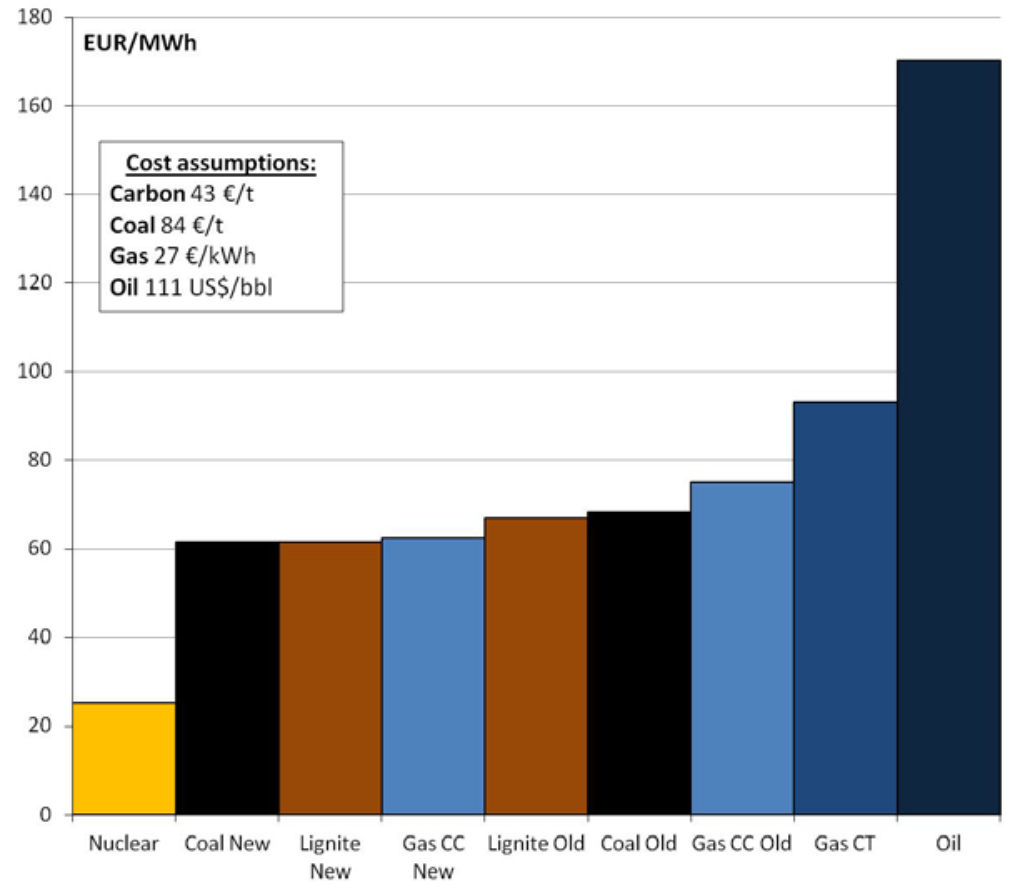

Figure 1: Variable generation cost. 


\section{Demand}

For all scenarios, German net power demand equals 535 TWh per year, including industry demand. This is equal to the 2010 realization of net demand (TSO 2012). While total yearly demand is fixed in the model, its actual repartition over time is endogenous. Demand is determined through a pricesensitive linear demand function with elasticity -0.1 . Growth of the reference demand outside Germany is set at 9.3\% absolute growth between 2011 and 2030 .

\section{Storage \& DSM}

Three storage technologies are included as measures to flexibilize supply: Adiabatic Compressed Air Storage (aCAES; 4 GW and 16 GWh in Germany), Pump Storage (9 GW and 60 GWh in Germany) and Battery storage (5 GW and $40 \mathrm{GWh}$ in Germany). The aCAES figure is half of the potential identified for Germany in Gillhaus et al. (2006). Three categories of DSM possibilities are included as measures to flexibilize demand. The cost for shifting consumer load is described with a step-wise increasing cost function in order to account for consumer heterogeneity: Low-cost household DSM (3 €/MWh), medium-cost commercial DSM (5 €/MWh) and high-cost industrial DSM (10 €/MWh). Up to $20 \%$ of the reference demand level can be shifted within a range of 2 hours.

\section{Grid}

Regarding the grid structure for 2030 (topology and capacities) we refer to the work performed in Boldt et al. (2012) and the recently published plans of the German Transmission System Operators (TSO 2012). Their projections take into account the Ten-Year Network Development Plan of the European Transmission System Operators and further planned projects. The application includes 41 nodes, 263 lines in the AC grid and 50 DC lines.

\section{Scenarios}

8 scenarios are established which allow for a detailed insight into the effect of storage, DC lines and power plant investment on grid congestion. The reference scenario (1) is characterized by the assumptions of the TSO Grid Development Plan scenario B 2032 regarding new transmission line projects and the existence of storage facilities. Alternatively, we propose a storage scenario (2a) in which we add two types of storage facilities in Germany as well as the possibility of demand-side-management (DSM), while holding the grid structure unmodified. A No-HVDC-scenario (2b) describes the same situation as in 2a but without HVDC lines. A Few-HVDC-scenario (2c) includes just a subset of the HVDC lines proposed by the TSOs. A power-plant-placing scenario with the proposed HVDC lines (3) runs scenario 1 with endogenous generation capacities. The same holds for the power-plant-placing scenarios with storage and HVDCs (3a), without HVDC (3b) and with few HVDC (3c). Table 3 summarizes the main scenario characteristics.

Table 3: Scenario overview.

\begin{tabular}{|l|c|c|c|c|}
\hline Scenario & DSM & Storage & $\begin{array}{c}\text { German } \\
\text { HVDC }\end{array}$ & $\begin{array}{c}\text { Power } \\
\text { plant }\end{array}$ \\
\hline 1 - Reference & - & - & 28 GW & - \\
\hline 2a - Storage & $\checkmark$ & $\checkmark$ & 28 GW & - \\
\hline 2b - No HVDC & $\checkmark$ & $\checkmark$ & - & - \\
\hline 2c - Few HVDC & $\checkmark$ & $\checkmark$ & $14.6 \mathrm{GW}$ & - \\
\hline 3 - 1 with investment & - & - & $28 \mathrm{GW}$ & $\checkmark$ \\
\hline 3a - 2a with investment & $\checkmark$ & $\checkmark$ & $28 \mathrm{GW}$ & $\checkmark$ \\
\hline 3b - 2b with investment & $\checkmark$ & $\checkmark$ & - & $\checkmark$ \\
\hline 3c - 2c with investment & $\checkmark$ & $\checkmark$ & $14.6 \mathrm{GW}$ & $\checkmark$ \\
\hline
\end{tabular}




\section{Results}

\subsection{Generation}

Figure 2 shows the generation pattern over the whole year in hourly resolution. Lignite and coal power plants are used as base load technologies unless RES feed-in is too strong. Note that at the assumed carbon price of $43 € / t$, gas power plants are still called after coal-fired plants in the merit order (not taking into account cycling cost). Gas power plants are only called upon at few occasions, in times where renewable feed-in is weak. Additionally, gas power plants are used during short intervals in periods of high fluctuations of renewable energies due to their low ramping costs. This pattern pertains to all scenarios and is exemplarily pictured for the reference scenario in Figure 2. Details on the usage of different several generation technologies can also be found in Table 4, where different scenarios are compared. The table demonstrates that all fossil-fired plants are increasingly used as HVDC transmission capacities are eliminated or reduced (3b, 3c). The scenarios with endogenous investment shift the power mix towards increased usage of new gas-fired power plants, to the detriment of all other fossilfired plants. Oil power plants are not used at any instance anymore for they are too expensive with the assumed $43 € / t \mathrm{CO}_{2}$ prices in 2030. The system-wide share of renewable energy sources lingers around the 52\% mark with slight deviations. Storage and DSM improve the share of RES in Germany slightly from $76.3 \%$ to $76.5 \%$ in the presence of HVDC lines. Scenarios $2 \mathrm{~b}$ and $2 \mathrm{c}$ with no to few HVDC lines produce a lower system-wide RES share than other scenarios. This suggests that HVDC is indeed used to promote the RES share in the system. We find a systematic negative effect of endogenous power plant investment on the RES share which is a pretty obvious result.

The net power consumption is in line with the TSO assumptions of 535 TWh in Germany (TSO 2012). A constraint in the model ensures this amount of yearly demand. Power production levels in Germany are lower than the demand level in most scenarios. As power generation is short of demand, Germany is a net importer of electricity by 2030 in most scenarios, contrasting the situation of 2012. We owe this effect to the increased price differences between countries with fossil-based production versus those with constant hydro production (Scandinavia) and nuclear energy (i.e. France). As German prices increase more than proportionately to some neighbours' power prices, there is increased import. The import rate increases with the use of storage and DSM in scenario 3a. HVDC lines seem to have an aggravating effect on electricity import of Germany. The more HVDC lines in Germany, the higher is the import rate of Germany. As HVDC disappear (scenario 2b), cheap northern German energy cannot be transported to southern demand zones and thus needs to be exported to neighbors.

We observe no systematic effect of HVDC lines, power plant investment and storage on demand levels by nature of the model constraints. The effect of storage and HVDC lines on the average German price level is somewhat counter-intuitive. The presence of HVDC lines puts upward pressure on German average prices. This could be due to the fact, that average prices are not weighed by importance of nodes. 


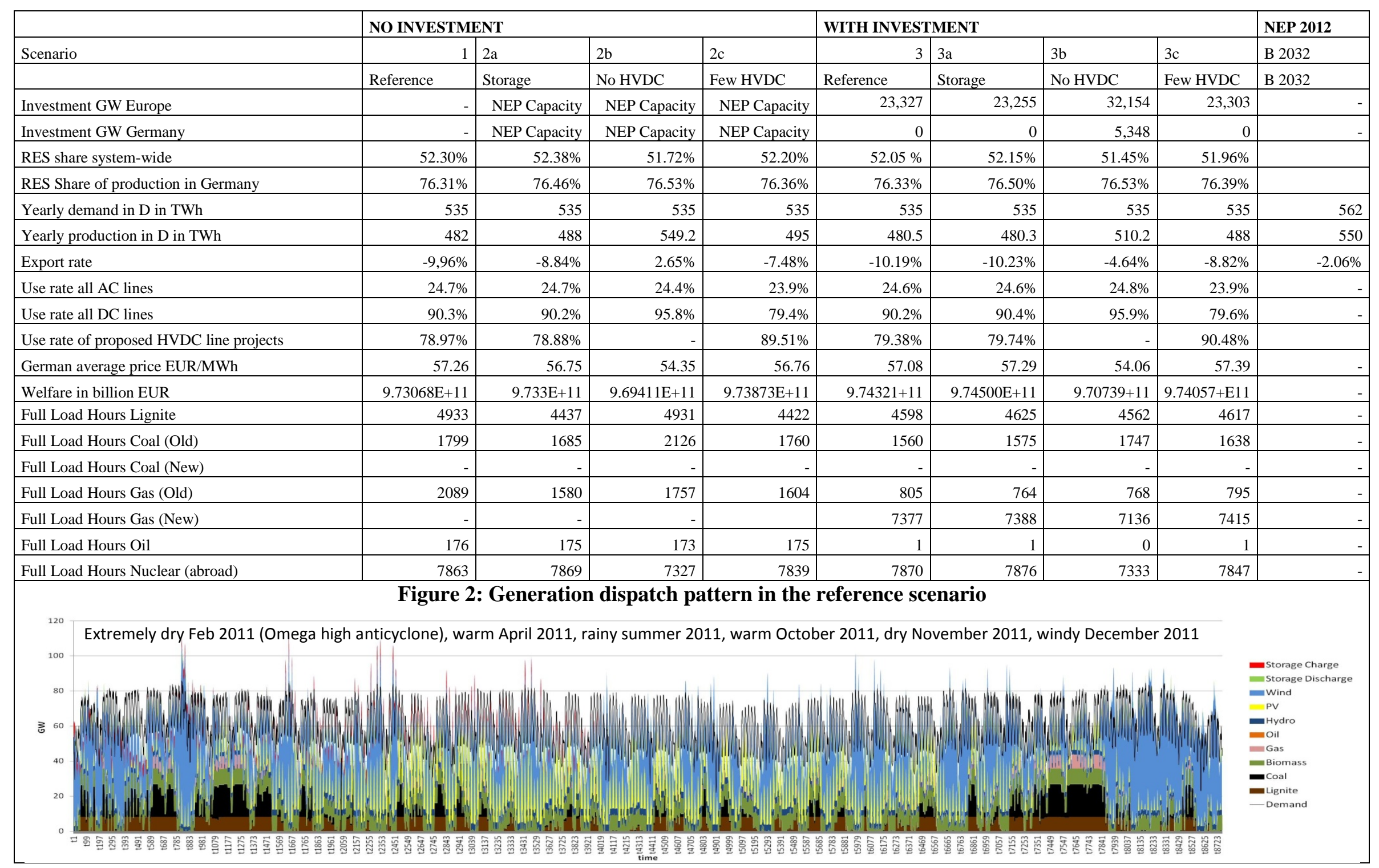

Table 4: Key results of scenarios. 


\subsection{Investment}

Results show that optimal capacity expansion levels for most technologies are much lower than previous "reference" studies propose for Germany (EWI et al. (2010); dena (2008); EC (2011)). This holds across all technologies. A possible explanation is that investment cost and carbon prices are set too low in the reference studies. Furthermore, many studies disregard dispatch inflexibilities of coal and lignite technologies and omit the possibilities of flexible demand and storage. However, we must admit that the model used here may undervalue the necessity of power plants because not accounting for uncertainty in renewable energy feed-in and demand. Table 4 shows the level of overall EU capacity expansion by 2030 for all scenarios. Capacity expansion in Germany is zero except in the absence of national HVDC lines in scenario 3b. Figure 3 shows that capacities are foremost planted in the southern to central zones, and Hamburg.

The model application suggests that investment into roughly 23-32 GW of gas-fired power plants be undertaken in south and Central Eastern Europe (Italy and Slovenia). We explain the (comparatively) low level of overall investment by the fact that other studies omit or underestimate the value of storage and DSM. According to Maurer et al. (2012), DSM and storage can only contribute little to reducing capacity needs. They argue that DSM and storage are designed to shift loads for few hours whereas supply shortages can occur with longer durations. The results here show that hydro pump storage and other facilities are also used for seasonal storage, thus showing great value in the short term as well as in the long term.

Regarding the technology choice, gas-fired power remains dominant in all scenarios, although it lies behind coal in the merit order. Concentration on gas-fired plants is also due to increased need for flexible resources with low ramping cost. 5,348 MW of gas-fired power plants are placed in Central and Southern German zones in scenario 3b, in the absence of HVDC lines (Figure 3). In all other scenarios, no power plant investment takes place in Germany. We conclude that even under strong decommissioning - as assumed in this study here - the model predicts hardly any need for new power plants in Germany with storage, demand-side-management and HVDC line extensions providing for sufficient alternatives. As indicated by the volatile generation profiles in Figure 2, new power plants - if built - will require good cycling capabilities. Such importance of cycling flexibility in the investment decision has also been pointed out in a related analysis carried-out by Fleten and Näsäkkälä (2010). The role of cycling cannot be accounted for in full detail in this study, since a more detailed analysis would require a stochastic model.

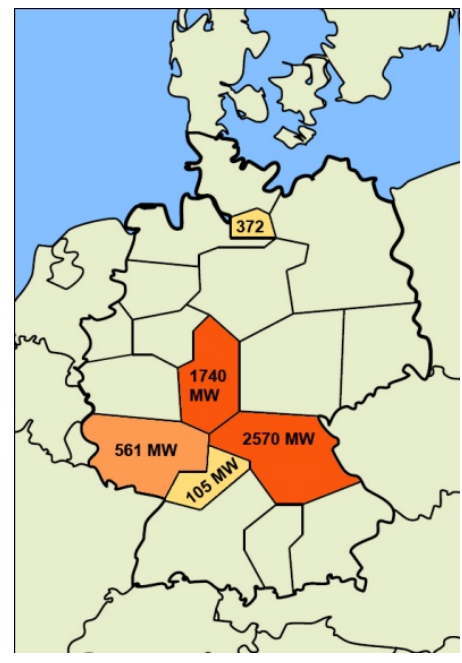

Figure 3: New generation capacity by 2030 in the absence of national HVDC lines 


\subsection{Congestion AC Grid}

Regarding the congestion patterns inside Germany, Figure 4 provides details for the standard grid (without German HVDC lines). Connections whose capacity limit is exhausted in less than $20 \%$ of the time are shown in yellow color. Connections with more than $40 \%$ of congested time and more than $60 \%$ are orange and red, respectively. Connections highlighted in dark red are overloaded more than $80 \%$ of the hours observed.

The comparison between the reference scenario (1) and the storage scenario with HVDC (2a) shows little changes. However scenario 3c demonstrates that the there is less congestion on a few southnorthern routes in absence of HVDC lines. This is true especially for the links 41-42, 24-25 and 83-25 in central southern Germany. The relatively strong bottlenecks in scenario $3 \mathrm{~b}$ can be relieved by the placement of 14.6 GW of HVDC lines in scenario 3c. Overall, we conclude that in scenario 3c, a reduced amount of HVDC capacity is a sufficient measure to avoid severe shortages in the domestic AC grid. Scenario 3c shows that 14.6 GW of HVDC lines are able to bringing congestion in the German power grid to a level relatively close to the reference scenario with 28 GW HVDC capacity. The placement of additional power plants (ca. 5.3 GW in Germany) in scenario 3b is not sufficient to relieve bottlenecks to the level of the reference scenario.

1 - Reference

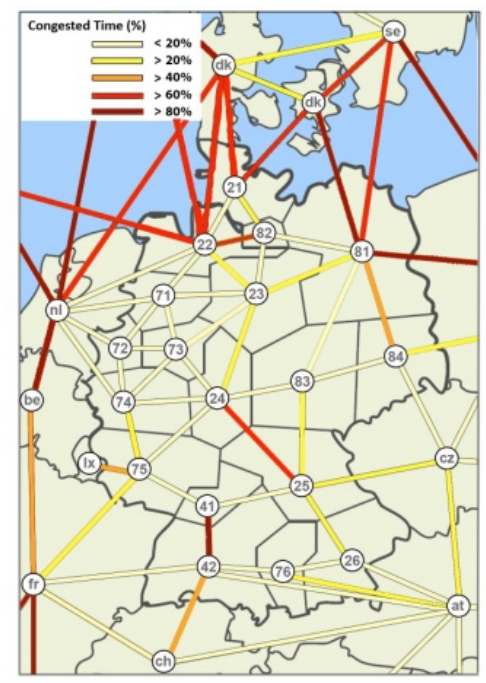

3b - Storage but no HVDC

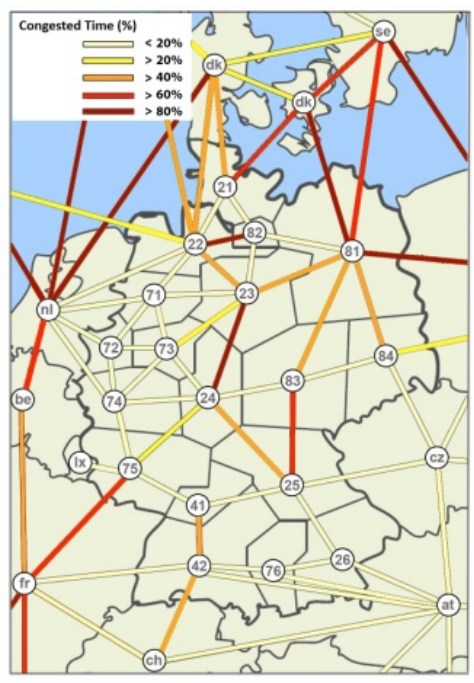

3c - 14.6 GW HVDC

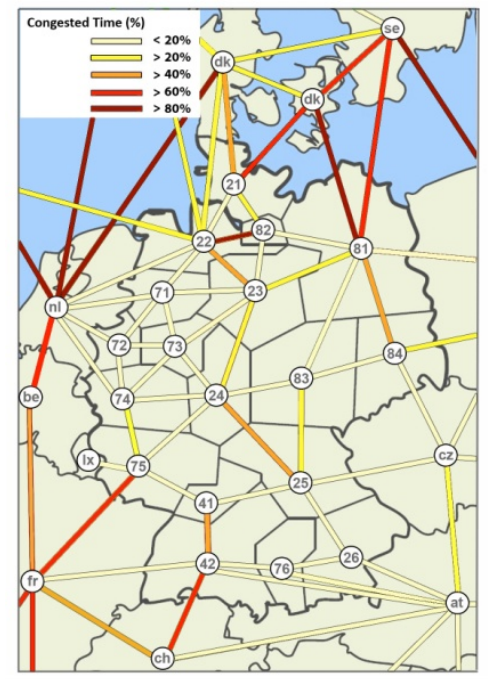

Figure 4: Congestion patterns in the standard grid

\subsection{Congestion on HVDC lines proposed in the German Grid Development Plan 2012}

While the HVDC lines proposed by TSOs contribute to less congestion in the AC grid, the HVDC lines themselves are mostly used to a high extent, as plotted in Figure 5. The figure only pictures the situation in the reference scenario. Its structure remains unchanged in other scenarios, though. The average use rate is depicted on the right side of the graph and it is consistently high for most lines, except for some lines on the north-south corridors B, C and D. The left side shows the hours of congestion as percentage. We see that some HVDC lines of the C Corridor between zones 21, 22 and the southern zones 42 and 25 are overloaded over $40 \%$ of the time. Most lines on the C Corridor are often overloaded. Given the large dimensions of the range of $12 \mathrm{GW}$ of transmission capacity of corridor C, this is an interesting result. The large capacity of this connection appears to be fully justifiable. The right part of the same chart shows that some lines in the Northwest part of the Republic have high average usage rates, although congestion is not as frequent as in the corridor C. This holds particularly 
for the HVDC transmission line 1 from Emden to Osterath (22-72), which has a high average utilization rate over $85 \%$ - yet it is used to full capacity less than $40 \%$ of the time. The situation is quite different for HVDC lines in the southwest and northeast. The average utilization of the HVDC links 10 from Gustrow to Meitingen (81-76) and 9 from Lauchstädt to Meitingen (83-76) are relatively low. The same is true for the HVDC transmission line 2 from the Rhenanian lignite mining area in Osterath to Philipsburg (72-41) and Elsfleth-Philipsburg (22-41). One might raise the question of the lines' usefulness. Due to the relatively low utilization of some HVDC lines, we investigate scenarios which deviate from the configuration of an HVDC network as proposed by the TSOs. Due to the nonexistence of HVDC transmission capacity in scenarios $2 b$ and $3 b$, congestion is transferred from the DC to the AC grid where new bottlenecks occur. In scenarios 2c and 3c, we propose the construction of only 14.6 GW of HVDC lines instead of $28 \mathrm{GW}$. It can be seen that the remaining HVDC lines are in good utilization of around $90 \%$ with a positive impact on the overall network. A value of $90 \%$ comes close to the use rates of traditional HVDC interconnectors between countries.

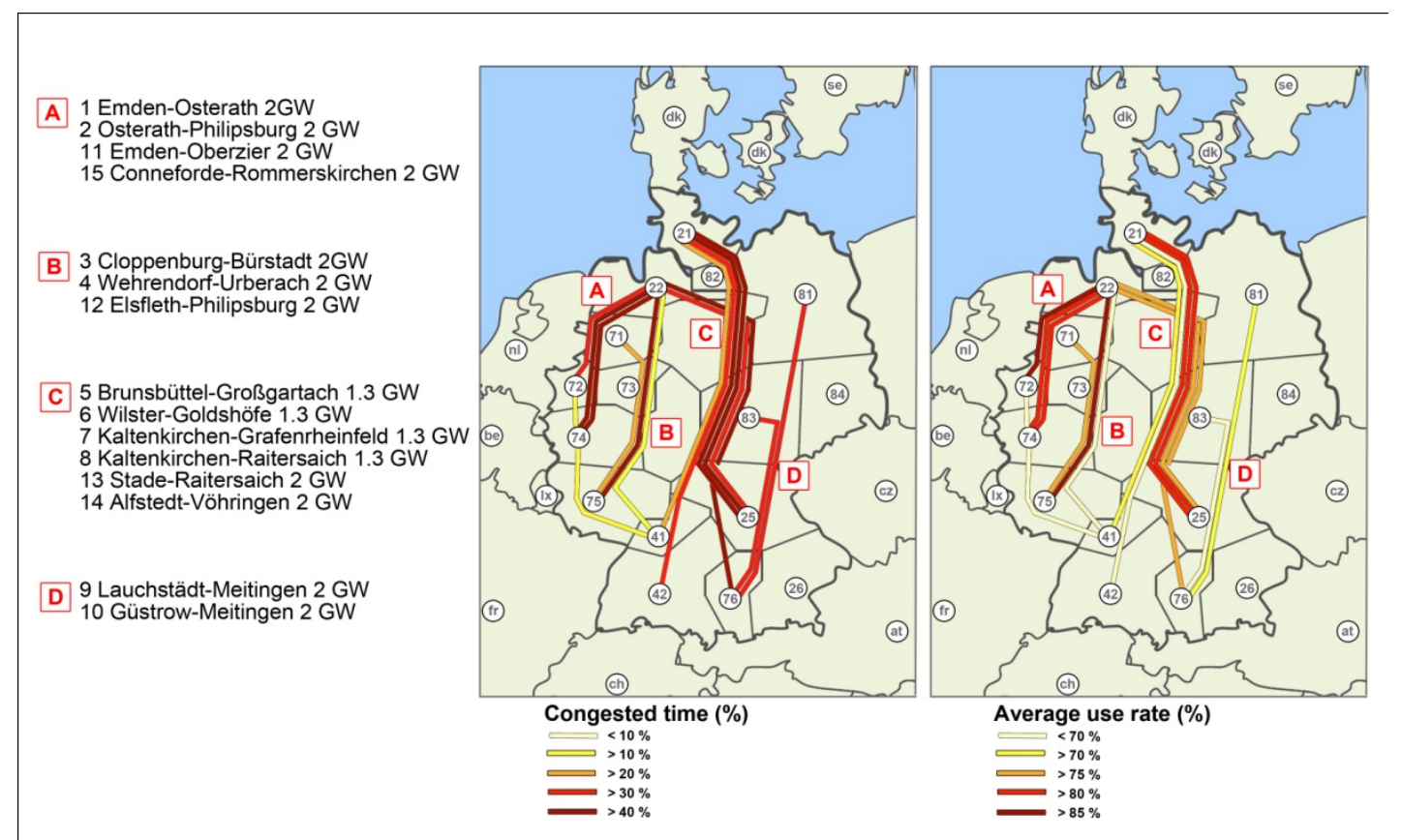

Figure 5: Congestion on HVDC lines proposed in the German Grid Development Plan 2012 (reference scenario)

A further detailed analysis of congestion patterns on the different corridors is illustrated in Figure 6. All in all, corridors B \& C are seldomly used to capacity (less than $10 \%$ of the time). Corridor A and B are used to full capacity at less than $20 \%$ of the time. The use rate of corridor D is lowest of all corridors, followed by corridor B. Note that use rates and congested times within corridor $\mathrm{C}$ vary greatly, as indicated in Figure 5. In scenario 3a, storage seems to be complementary to better usage of HVDC lines in times where lines are not congested. In scenario 3c, the two corridors are almost always used to full capacity. We may conclude from the analysis above, that the necessity of the HVDC lines proposed in the TSO plan varies greatly case by case. While all corridors do show some positive impact on relieving congestion in the AC grid, there seem to be some individual links which have little to no positive impact. A prioritization of HVDC projects may thus be a good step to reduce costs of grid expansion while equally ensuring the advantages that HVDC lines provide for the grid system. 
Scenario 1 - Reference

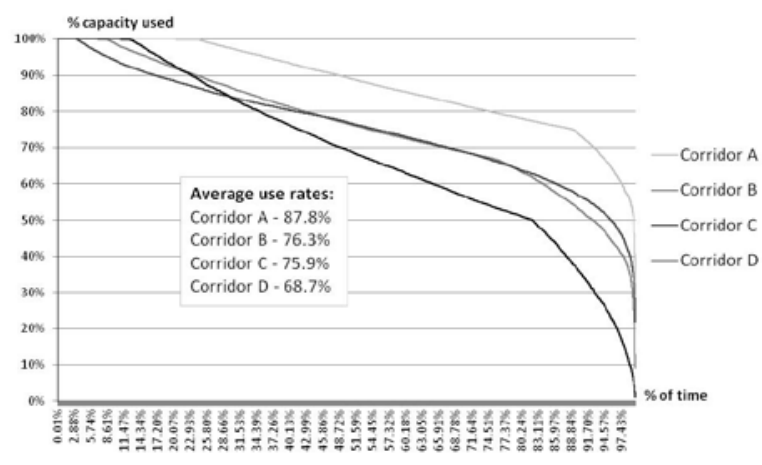

Scenario 3c - Only 2x2GW HVDC lines

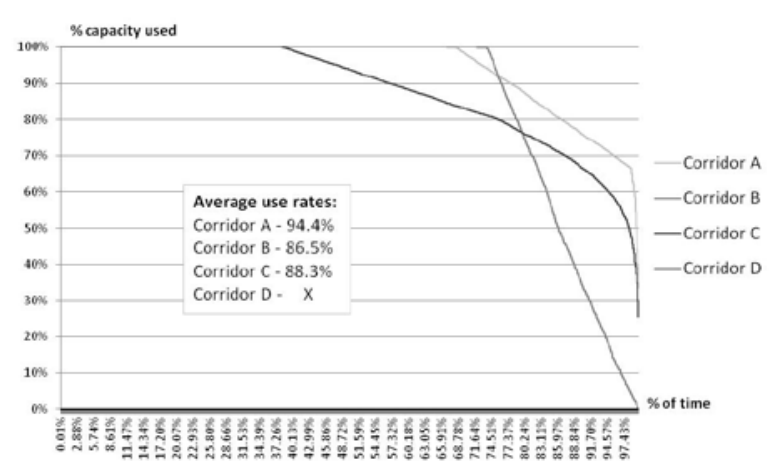

Scenario 3a Storage \& Investment

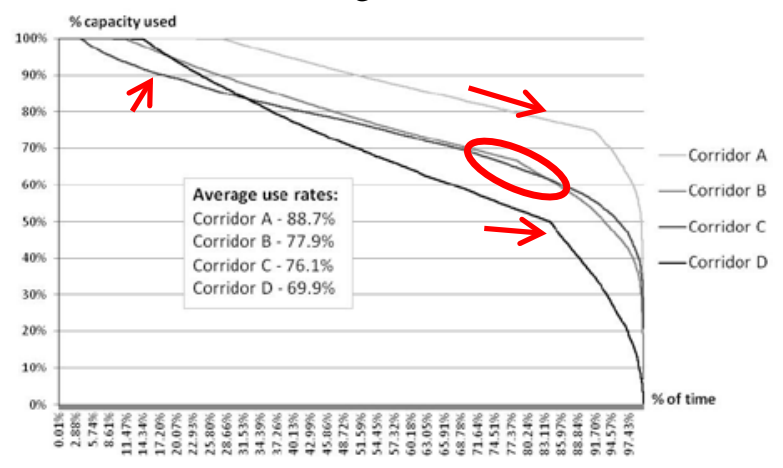

Indications in Grid Development Plan

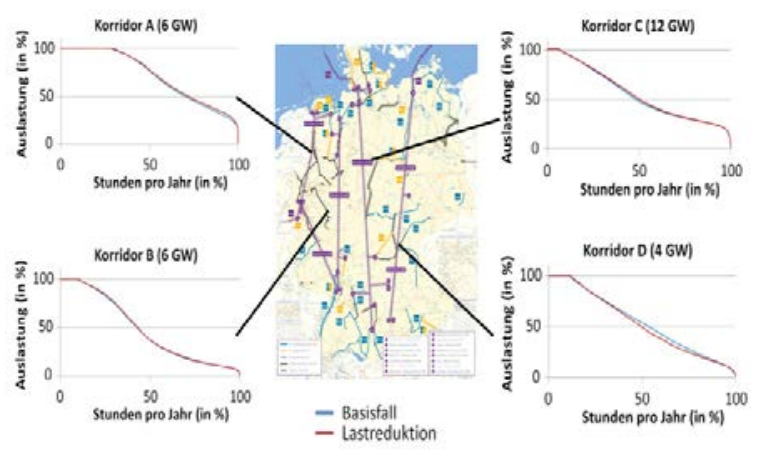

Figure 6: Congestion patterns on HVDC lines proposed in the German Grid Development Plan 2012 and comparison to results here

Source: Own illustration and TSO (2012, p.169)

\subsection{Price differences}

A basic assumption of the model application is that German producers and consumers face nodal prices. While such market design is not in force today, we assume that it is going to be implemented by 2030. As shown in Figure 7, nodal prices within Germany align around 54-61 €/MWh in the reference scenario. Regional differentiation is low. This result can easily explained by the balancing effect of massive HVDC capacity. As soon as this is left out, prices between regions drift apart quite heavily, as shown in the middle section of Figure 7. A huge price differential between exporting northern zones and importing southern zones emerges. The right side of the graphs demonstrates that DSM, storage management and power plant placing manage to bring the price structure closer to its reference case even in the presence of only 14.6 GW of HVDC lines. However, effects are only local, and Germany remains affected by price developments in neighboring states. 
HVDC
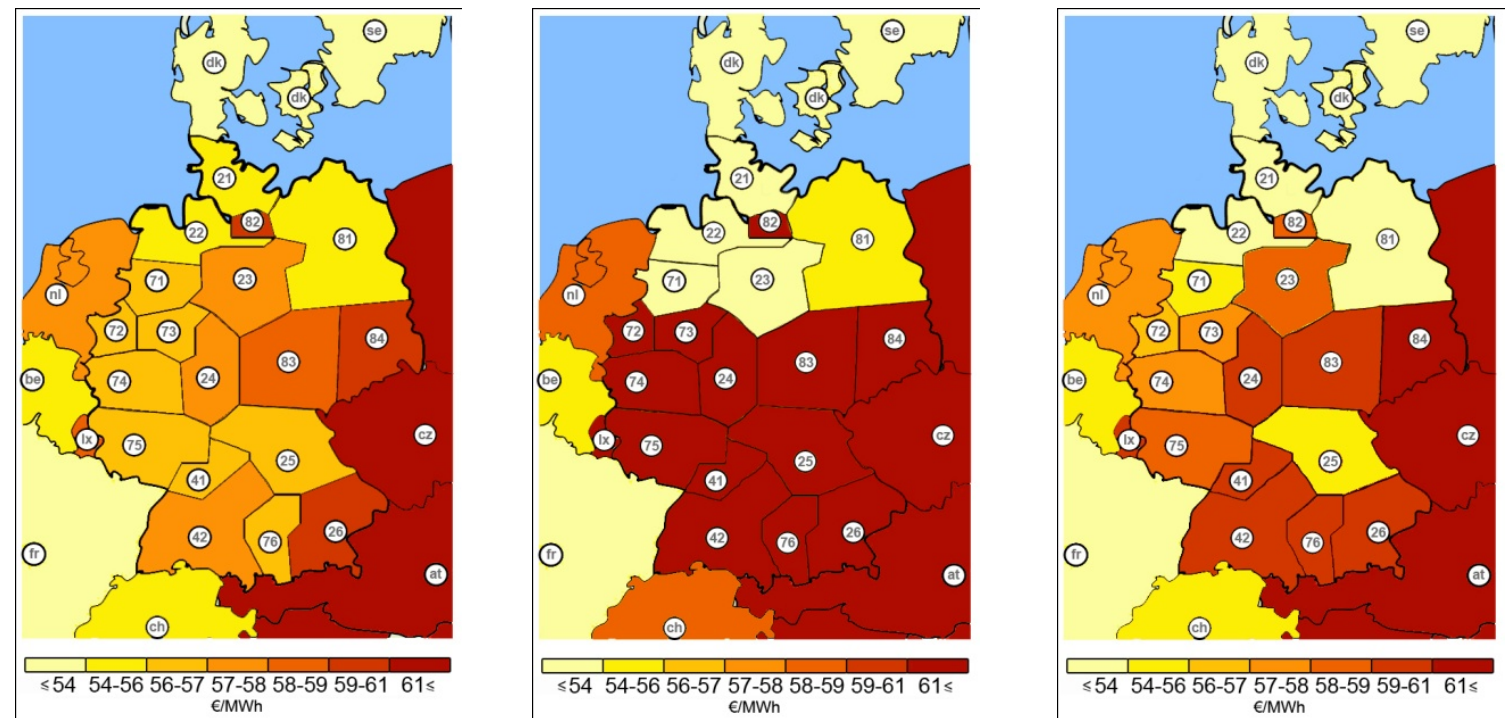

Figure 7: Prices in different scenarios

\section{Conclusions}

This paper presents a model for the analysis of power plant placing and grid congestion. An application is done for Central Europe in 2030 and congestion patterns are compared to the Grid Development Plan of the German TSOs (TSO 2012). We find that HVDC lines as proposed in the German grid development plan are useful in relieving overall congestion. However, some lines have less impact on overall congestion than others and could be marked as second priority. A prioritization of HVDC projects would be an appropriate measure to ensure that the positive effects of HVDC lines prevail.

The analysis shows that a mix of few HVDC lines, storage, DSM and the placement of power plants can contribute to alleviating the need in expanding power transmission capacity. Overall investment levels into generation capacity are way lower in our results compared to related studies (e.g. dena (2008); EC (2011); EWI et al. (2010); Maurer et al. (2012), TSO (2012)). We conclude that many comparable models over-estimate the necessity of power plants by omitting the flexibilities offered by storage, DSM and increased grid capacities. We suggest it would be beneficial to coordinate the planning of power plant investment along with grid system planning.

The need for transmission capacity expansion and generation capacity investments are the focus of the application presented here. Whether sufficient investment incentives are present in today's liberalized energy-only markets should is subject of another line of research (Sauma \& Oren 2009; Milstein \& Tishler 2012). Similarly, subjects such as security of supply and risk aversion of planners deserve attention (van der Weijde \& Hobbs 2012) and should possibly be modeled with tools that include uncertainty in demand and renewable energy feed-in. 


\section{Appendix}

\begin{tabular}{|c|c|c|}
\hline \multirow[t]{6}{*}{ Sets } & $s$ & Set of all plant types \\
\hline & $n$ & Set of all nodes \\
\hline & $l$ & Set of all line \\
\hline & $d c l$ & Set of all DC lines \\
\hline & $t$ & Set of all times/hours \\
\hline & st & Set of all storage types \\
\hline \multirow{22}{*}{$\begin{array}{l}\text { Parame- } \\
\text { ters }\end{array}$} & $\varepsilon$ & Demand elasticity at reference point \\
\hline & $\lambda$ & Factor defining load levels \\
\hline & $A C_{p_{\max }}(l)$ & Maximum capacity of line $l$ \\
\hline & $D C_{p_{\max }}(l)$ & Maximum capacity of line $d c l$ \\
\hline & $D_{S S} M_{M A X_{h}}(t, n)$ & Maximum capacity of demand-side management at high cost \\
\hline & $D S M_{M A X_{l}}(t, n)$ & Maximum capacity of demand-side management at low cost \\
\hline & $D S M_{M A X_{m}}(t, n)$ & Maximum capacity of demand-side management at medium cost \\
\hline & $S_{I N \max }(s t, n, t)$ & Maximum storage inflow \\
\hline & $S_{\text {OUT } \max }(s t, n, t)$ & Maximum storage outflow \\
\hline & $S_{c a p_{\max }}(s t, n)$ & Storage capacity limit \\
\hline & $\operatorname{hydro}_{\max }(t, n)$ & Maximum of energy generation by hydro powered energy plants \\
\hline & $\operatorname{Cost}_{D S M}(s)$ & Cost for DSM \\
\hline & $\operatorname{Cost}_{I N V E S T}(s, n)$ & Investment Costs for plant type $s$ in node $n$ \\
\hline & Cost $_{\text {ramp }}(s)$ & Marginal ramping costs \\
\hline & $D C_{\text {incidence }}(d c l, n)$ & Incidence matrix \\
\hline & $G_{\max }(n, s)$ & Maximum of generation capacity at node $n$ of plant $s$ \\
\hline & $\operatorname{Lim}_{\text {ramp }}$ & Limit of ramped up generation capacity \\
\hline & Perc $r a m p$ & Load Gradient as percentage of nominal capacity \\
\hline & $S_{e f f}(s t)$ & Conversion efficiency storage \\
\hline & $p_{r e f}(t)$ & Reference price of demand function at $t$ \\
\hline & $p v_{\max }(t, n)$ & Maximum of energy generation by hydro photovoltaic energy plants \\
\hline & $q_{\text {ref }}(t)$ & Reference demand at $t$ \\
\hline
\end{tabular}


$\operatorname{wind}_{\max }(t, n) \quad$ Maximum of energy generation by wind powered energy plants

$c(s) \quad$ Cost for plant type $s$

$m(t, n) \quad$ Slope of demand function

ptdf $(l, n) \quad$ Power transfer distribution factor concerning node $n$ and line $l$

$\operatorname{rev}(s) \quad$ Factor defining the availability of plant type $s$

$x \quad$ Predetermined level of yearly demand

Variab- $\quad A C_{\text {lineflow }}(l, t) \quad$ Lineflow on $l$

les

$A C_{\text {netinput }}(t, n) \quad$ Net input on node $n$

$\operatorname{Cost}_{\text {var }}(t) \quad$ Total generation cost

$D C_{\text {lineflow }}(d c l, t)$ Lineflow on $d c l$

$D C_{\text {netinput }}(t, n) \quad$ Net input at node $n$

$q_{\text {area }}(t) \quad$ Area under demand function

W Welfare

Positive $\quad \operatorname{DSM}_{\text {OUT }_{h}}(t, n) \quad$ DSM shifting load at high cost

Variab-
les $\operatorname{DSM}_{\text {OUT }_{l}}(t, n) \quad$ DSM shifting load at low cost

$\operatorname{DSM}_{\text {OUT }}(t, n) \quad$ DSM shifting load at medium cost

$D S M_{I N_{h}}(t, n) \quad$ DSM adding load at high cost

$D S M_{I N_{l}}(t, n) \quad$ DSM adding load at low cost

$\operatorname{DSM}_{I N_{m}}(t, n) \quad$ DSM adding load at medium cost

$I(s, n) \quad$ Investment into generation capacity

$S_{I N}(s t, n, t) \quad$ Storage inflow

$S_{L E V E L}(s t, n, t) \quad$ Storage level

$S_{\text {OUT }}(s t, n, t) \quad$ Storage outflow

$g_{u p}(t, s, n) \quad$ Generation change from one period to the next

$q(t, n) \quad$ Demand at node $n$

$G(n, s, t) \quad$ Generation of plant type $s$ of firm $f$ at node $n$ 


\section{List of References}

Boldt, J. et al., 2012. Renewables in the Grid - Modeling the German Power Market of the Year 2030. TU Dresden Electricity Markets Working Paper, WP-EM-48, p.91.

Dee, D. et al., 2011. The ERA-Interim Reanalysis: Configuration and Performance of the Data Assimilation System. Quarterly Journal of the Royal Meteorological Society, 137(656), pp.553597.

dena, 2010. dena Grid Study II. Integration of Renewable Energy Sources in the German Power Supply System from 2015 - 2020 with an Outlook to 2025, Berlin: Deutsche Energie-Agentur $\mathrm{GmbH}$ - dena.

dena, 2008. Kurzanalyse der Kraftwerks und Netzplanung in Deutschland bis 2020 (mit Ausblick auf 2030), Berlin: Deutsche Energie-Agentur GmbH. Available at: http://www.erfurt.ihk.de/files/11928E85D21/2008_dena_studie.pdf [Accessed January 15, 2012].

Dietrich, K., Leuthold, Florian \& Weigt, Hannes, 2010. Will the Market Get it Right? The Placing of New Power Plants in Germany. Zeitschrift fuer Energiewirtschaft, 34(4), pp.255-265.

EC, 2011. Energy Roadmap 2050, Brussels: European Commission.

EcoFys et al., 2011. Renewable Energy Policy Country Profiles - 2011 version, Available at: http://www.reshaping-res-policy.eu [Accessed January 15, 2012].

Elberg, C. et al., 2012. Untersuchungen zu einem zukunftsfähigen Strommarktdesign, Berlin: Bundesministerium für Wirtschaft und Technologie (BMWi.

ENTSO-E, 2009. System Adequacy Forecast 2009-2020, Brussels: UCTE Union for the Coordination of Transmission of Electricity.

Eurostat, 2011. Energy, Transport and Environment Indicators, Belgium: Office for Official Publications of the European Communities.

EWI, PROGNOS \& GWS, 2010. Energieszenarien für ein Energiekonzept der Bundesregierung, Basel/Cologne/Osnabruck: Commissioned by the Federal Ministry for Economics and Technology. Available at: http://www.bmu.de/energiewende/downloads/doc/46367.php [Accessed August 8,2011$]$.

Fleten, S.-E. \& Näsäkkälä, E., 2010. Gas-fired power plants: Investment timing, operating flexibility and CO2 capture. Energy Economics, 32(4), pp.805-816.

Gillhaus, A., Crotogino, F. \& Hübner, S., 2006. Verbesserte Integration großer Windstrommengen durch Zwischenspeicherung mittels CAES, Aachen: IEAE RWTH Aachen, ALSTOM Power, EcoFys, EOn Energie, KBB, IAEW, REPower, Vattenfall Europe Transmission. Available at: http://www.bine.info/fileadmin/content/Publikationen/Projekt-Infos/Zusatzinfos/200705_Abschlussbericht.pdf [Accessed October 11, 2012].

Haller, M., 2012. CO2 Mitigation and Power System Integration of Fluctuating Renewable Energy Sources: A Multi-Scale Modeling Approach. PhD Thesis. Berlin: Technical University Berlin. 
Haller, Markus, Ludig, S. \& Bauer, N., 2012. Decarbonization scenarios for the EU and MENA power system: Considering spatial distribution and short term dynamics of renewable generation. Energy Policy, 47, pp.282-290.

IEA, 2011. World Energy Outlook 2011, Paris: OECD Publishing.

IWR, 2012. Der IWR-Windertragsindex® für Regionen, IWR. Available at: http://www.iwr.de/wind/wind/windindex/index.html.

Knopf, B. et al., 2011. Der Einstieg in den Ausstieg: Energiepolitische Szenarien für einen Atomausstieg in Deutschland, Potsdam: Potsdam-Instituts für Klimafolgenforschung.

Leuthold, F., Weigt, H. \& Hirschhausen, C., 2012. A Large-Scale Spatial Optimization Model of the European Electricity Market. Networks and Spatial Economics, 12(1), pp.75-107.

Maurer, C., Tersteegen, B. \& Zimmer, C., 2012. Anforderungen an den konventionellen Kraftwerkspark - wieviel und welche Kraftwerkskapazitaet wird benoetigt? Zeitschrift fuer Energiewirtschaft.

Milstein, I. \& Tishler, A., 2012. The inevitability of capacity underinvestment in competitive electricity markets. Energy Economics, 34(1), pp.62-77.

Nagl, S., Fürsch, M. \& Lindenberger, D., 2012. The Costs of Electricity Systems with a High Share of Fluctuating Renewables - a Stochastic Investment and Dispatch Optimization Model for Europe, Cologne: EWI. Available at: http://www.ewi.unikoeln.de/fileadmin/user_upload/Publikationen/Working_Paper/EWI_WP_1201_Costs_of_electricity_systems_with_a_high_share_of_fluctuating_ren.pdf [Accessed April 18, 2012].

Platts, 2011. World Electric Power Plants Database: Global Price Assessments and Indices. Available at: http://www.platts.com/Products/worldelectricpowerplantsdatabase [Accessed January 25, 2011].

Sauma, E.E. \& Oren, S.S., 2009. Do generation firms in restructured electricity markets have incentives to support social-welfare-improving transmission investments? Energy Economics, 31(5), pp.676-689.

Scorah, H., Sopinka, A. \& van Kooten, G.C., 2012. The economics of storage, transmission and drought: integrating variable wind power into spatially separated electricity grids. Energy Economics, 34(2), pp.536-541.

SFV, 2012. Bundesweite Aufnahme der monatlichen Stromertragsdaten von PV-Anlagen, Solarenergie-Förderverein Deutschland e.V. Available at: http://www.pv-ertraege.de/cgibin/pvdaten/src/region_uebersichten.pl/kl.

TSO, 2012. Netzentwicklungsplan Strom 2012 - Entwurf der Übertragungsnetzbetreiber, Berlin: TenneT, 50 Hertz, Amprion and EnBW. Available at: http://www.netzentwicklungsplan.de/content/netzentwicklungsplan-2012 [Accessed May 30, 2012].

van der Weijde, A.H. \& Hobbs, B.F., 2012. The economics of planning electricity transmission to accommodate renewables: Using two-stage optimisation to evaluate flexibility and the cost of disregarding uncertainty. Energy Economics. Available at: http://linkinghub.elsevier.com/retrieve/pii/S0140988312000436 [Accessed August 5, 2012]. 